\title{
Apolipoprotein E Genotype and Expression Correlated with Hepatitis C Virus Genotype and Infection
}

\author{
Gyu-Nam Park', Hyun-Jung Jo ${ }^{1}$, Hye-Ran Kim ${ }^{1}$, Min-Ju Kim¹ , Kyung-A Shin², \\ Seung-Bok Hong ${ }^{3}$ and Kyung- Soo Chang ${ }^{1 *}$
}

1Department of Clinical Laboratory Science, Catholic University of Pusan, Busan, Republic of Korea

2Department of Clinical Laboratory Science, Shinsung University, Dangjin, Republic of Korea

${ }^{3}$ Department of Clinical Laboratory Science, Chungbuk Health \& Science University, Cheongwon, Republic of Korea

\author{
Corresponding \\ Kyung Soo Chang \\ Department of Clinical Laboratory \\ Science, College of Health Sciences, \\ Catholic University of Pusan, Bugok \\ 3-dong, Geumjeong-gu, Busan 609-757, \\ Korea. \\ Phone : +82-51-510-0565 \\ Fax : +82-51-510-0565 \\ E-mail : kschang@cup.ac.kr
}

Received : February 15, 2019

Revised : March 19, 2019

Accepted : March 20, 2019
No potential conflict of interest relevant to this article was reported.

Copyright (C) 2018 Journal of Bacteriology and Virology

(C) This is an Open Access article distributed under the terms of the Creative Commons Attribution Non-Commercial License (http://creativecommons.org/ license/by-nc/3.0/)
The hepatitis $\mathrm{C}$ virus (HCV) is a globally prevalent human pathogen that causes persistent liver infections in most infected individuals. Several studies reported that HCV particles are enriched in apolipoprotein E (apoE) and that apoE is required for HCV infectivity and production. However, the relationship between apoE gene polymorphisms and HCV genotypes in patients with HCV is less well understood. The aim of this study was to investigate the association between apoE gene polymorphism and HCV genotypes in patients. The HCV genotypes were identified among the 124 patients infected with $\mathrm{HCV}$, and the genetic characteristics of the HCV genotype were analyzed. In addition, the results of the clinical laboratory test were comparatively analyzed according to the classified genotypes. Both HCV $1 \mathrm{~b}(n=80)$ and $2 \mathrm{a}(\mathrm{n}=42)$ patients had higher AFP, AST, ALT, ALP, $\gamma$-GTP, apoB, and apoE values compared with the normal control group. In particular, apoB and apoE levels were statistically significantly higher in the HCV 2a patients $(P<0.05)$ and apoE levels were significantly higher in the HCV $1 \mathrm{~b}$ patients $(P<0.000)$. According to the results the patients with HCV genotype $1 \mathrm{~b}$ showed higher values of liver damage related indicators and apoB expression than the patients with HCV genotype $2 \mathrm{a}$. The fat related indicators and apoE expression were not different between the two major HCV genotypes ( $2 a$ and $1 b)$. We anticipate that the apoE $\varepsilon 3$ allele is the most common type in HCV genotype $1 \mathrm{~b}(89.2 \%)$ and $2 \mathrm{a}(91.7 \%)$. As a result of apoE genotyping, we confirmed an association with HCV infection and the apoE 83 allele. However, the ratios of the apoE $\varepsilon 3$ allele among the patients with genotype $1 \mathrm{~b}$ and $2 \mathrm{a}$ were similar to each other.

Key Words: Apolipoprotein E, Hepatitis C virus, Genotype

\section{INTRODUCTION}

The hepatitis C virus (HCV) belongs to the family Flaviviridae and is a single strand RNA virus. Its total gene length is 9,600 bp, and it is characterized by the high probability of being mutated. The currently known HCV genotypes include $1-11$, with the subtypes $a, b$, and c. Currently, genotypes up to HCV 6 can be clinically diagnosed $(1,2)$.

Globally, the number of hepatitis C patients has reached approximately 180 million, and the prevalence ratio is $2.8 \%$. Among the genotypes of $\mathrm{HCV}$, 
genotype 1 is the most prevalent, followed by genotype 2. These genotypes show differences by region; for example, genotype $1 \mathrm{a}$ is the most prevalent in Northern Europe and North America, and genotype $1 \mathrm{~b}$ is highly prevalent in East Asia and Europe. Genotype 2 also appears frequently in Northern Europe, North America, East Asia, and Europe, but in lower ratios than genotype 1. In South Korea, hepatitis $C$ is an infectious disease under sentinel surveillance, in which approximately 4,000 cases are reported every year, and its prevalence ratio in Korea is approximately $0.78 \%$. Of the diagnosed cases, genotype $1 \mathrm{~b}$ accounts for the highest ratio, followed by genotype $2 \mathrm{a}(1 \sim 4)$.

HCV genotypes have important meanings for diagnoses, because their sensitivity levels to antiviral agents are different from each other, leading to different treatment decisions. The antiviral agent' treatment performances against genotypes 1 and 4 have been reported to be lower, when compared to genotypes 2, 3, and 6 (5).

The correlations between HCV and the cholesterol level have been previously proven in many studies. Low cholesterol values are shown in HCV patients, and it has been reported that cholesterol pays an important role when HCVs infiltrate liver cells. More detailed studies have reported that low density lipoproteins (LDLs) and apolipoproteins from cholesterol contribute to an HCV infection and proliferation. Apolipoprotein $\mathrm{E}(\mathrm{apoE})$ and $\mathrm{B}$ are both components of very low density lipoprotein (VLDL) and are thought to play important roles in the HCV life cycle. In particular, ApoE plays an important role in moving the HCV viral particles to the liver cells (6 9). Based on these reports, studies to develop HCV treatment agents through anti-cholesterol functions are being actively conducted (10).

ApoE is one of the plasma protein, and it functions in the transport of cholesterol and lipids. apoE is classified as having $\varepsilon 2, \varepsilon 3$, or $\varepsilon 4$ alleles, and since these genetic polymorphisms are associated with some diseases, they are used in the diagnoses as well (11 13). However, the relationship between apoE gene polymorphisms and HCV genotypes in patients with HCV is less well understood.

Therefore, the purpose of the present study was to classify the genotypes of the HCVs isolated in Korea. Additionally, the genotypes would be compared with those isolated overseas, a quantitative analysis would be conducted on the blood apoB and apoE according to the HCV genotypes, and genetic polymorphisms of apoE would be identified to study the correlations between them.

\section{MATERIALS AND METHODS}

\section{Samples}

HCV ( $n=124)$ samples (serum and whole blood) were collected at Bundang Jaesang Hospital in 2012, and the HCV samples were defined by anti-HCV tests, looks for antibodies to the HCV. The normal control group $(n=100)$ was selected from clinically healthy people between 45 - 60 years old.

The samples were immediately stored at $-70^{\circ} \mathrm{C}$, and the patient's medical records were collected for the analysis of the clinical characteristics. This study was approved by the Institutional Review Board of Bundang Jaesang Hospital.

\section{HCV RNA isolation and amplification from serum}

The HCV RNA was isolated using Accuzol ${ }^{\mathrm{TM}}$ RNA extraction solution (Bioneer, Seoul, Korea), and the isolated RNA was resuspended in $50 \mu \mathrm{l}$ of $0.1 \%$ diethylpyrocarbonate (DEPC). To amplify the 5'UTR region of the HCV RNA for genotyping, a nested PCR was conducted. An initial denaturation was performed at $42^{\circ} \mathrm{C}$ for $60 \mathrm{~min}$, and at $95^{\circ} \mathrm{C}$ for 5 min. Thereafter, reverse-transcriptase PCR (RT-PCR) was performed for 35 cycles, with denaturation at $95^{\circ} \mathrm{C}$ for $1 \mathrm{~min}$, annealing at $50^{\circ} \mathrm{C}$ for $1 \mathrm{~min}$, and extension at $72^{\circ} \mathrm{C}$ for 1 min using a RT-PCR premix (Bioneer, Seoul, Korea). The primer set consisted of forward CTG TGA 
GGA ACT ACT GTC TT and reverse ACT CGC AAG CAC CCT ATC AG. A second PCR was performed for 25 cycles, with denaturation at $95^{\circ} \mathrm{C}$ for $30 \mathrm{sec}$, annealing at $55^{\circ} \mathrm{C}$ for $30 \mathrm{sec}$, and extension at $72^{\circ} \mathrm{C}$ for $30 \mathrm{sec}$ using a PCR premix (Bioneer, Seoul, Korea). The primer set consisted of forward TTC ACG CAG AAA GCG TCT AG and reverse TAT CAG GCA GTA CCA CAA GG

\section{HCV genotype analysis}

The amplicon was purified using a PCRmix purification kit (Cosmogenotech, Seoul, Korea), and the product was transferred for sequencing to Cosmogenetech (Seoul, Korea). The sequence of the HCV isolates and the sequences available in the GenBank database were used for the comparison. The sequences were aligned using MEGA 4.1 software, and their phylogenetic relationship was analyzed. For this, the Kimura-2-parameter distances wiere calculated using the neighbor-joining (NJ) algorithm. The reliability of the various phylogenetic groupings was evaluated by using the bootstrap test with 1,000 replications.

\section{Quantitative analysis of apolipoprotein B and E}

The Apolipoprotein B Human ELISA kit and Apolipoprotein E Human ELISA kit were used for analysis (Abcam, Cambridge, UK). The obtained serum was used for testing, and we followed the protocols thoroughly.

\section{ApoE genotyping}

The DNA was isolated using a DNA isolation kit (Cosmogenotech, Seoul, Korea) from whole blood. The isolated DNA was used for apoE genotyping, and an EzWayTM Direct ApoE Genotyping kit (Komabiotech, Seoul, Korea) was used. This kit is based on the multiplex PCR method, and the genotype was determined by electrophoresis in a $2 \%$ agarose gel (Fig. 1.)

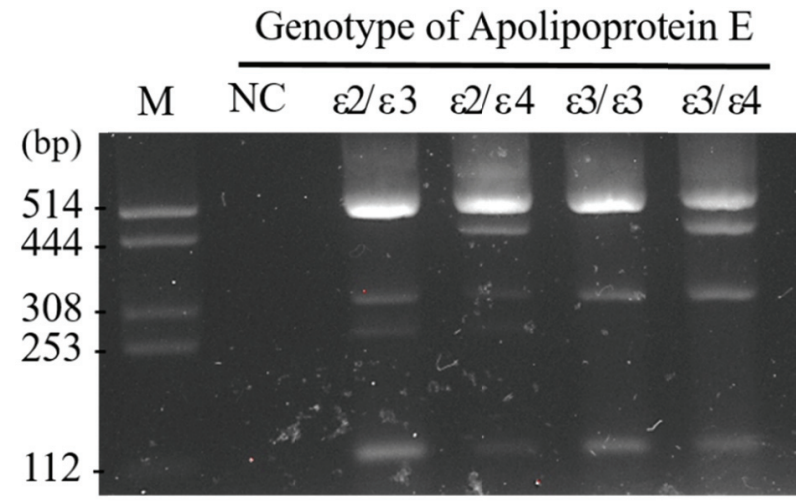

Figure 1. Electrophoresis results of apoE PCR products. lane 3: $\varepsilon 2 / \varepsilon 3(253,308 \mathrm{bp})$, lane 4: $\varepsilon 2 / \varepsilon 4(253,308,444$ bp), lane 5: $\varepsilon 3 / \varepsilon 3$ (308 bp), lane 6: $\varepsilon 3 / \varepsilon 4(308,444 \mathrm{bp})$

$M$, size marker $(112,253,308,444,514 \mathrm{bp})$; $N C$, negative control.

\section{Statistical analyses}

SPSS 18.0 statistical software was used for the data analysis, and continuous variables, like the clinical characteristics, were compared with the Student's t-test. Categorical variables, like apoE genotype, were compared vvith a cross tabulation test. P-values of $<0.05$ were considered statistically significant. 


\section{RESULTS}

\section{HCV genotype distribution and gene characteristics}

The HCV genotypes in the $124 \mathrm{HCV}$ patient' serum samples were analyzed, and as a result, the HCV genotypes could be identified in a total of 124 samples. The most frequently identified genotype was genotype $1 \mathrm{~b}$, which was identified in a total of 80 samples, accounting for $64.5 \%$ of all samples. Genotype 2a was identified in 42 samples, accounting for $33.9 \%$, and genotype 1 a was identified in 2 samples, accounting for $1.6 \%$ (Table 1).

Table 1. Distribution of HCV genotypes in HCV samples

\begin{tabular}{ccc}
\hline HCV genotype & $\mathrm{n}$ & $\%$ \\
\hline 1a & 2 & 1.6 \\
1b & 80 & 64.5 \\
2a & 42 & 33.9 \\
\hline Total & 124 & 100 \\
\hline
\end{tabular}

The isolated HCV genotypes were classified as shown in Table 2. Genes that were similar to each other based on the results of the gene analysis were grouped for analyses. Genotype $1 \mathrm{~b}$ sequences formed five major separated groups (namely KOR-A to E). Group KOR-A $(n=33)$ and KOR-B $(n=21)$ contained the majority of $1 b$ isolates. Five isolates identified genotype $1 b$, was not contained any other groups. Genotype 2a sequences formed four major separated groups (namely KOR-A to D). Group KOR-A $(n=16)$ and KOR-B $(n=19)$ contained the majority of $2 a$ isolates. Three isolates identified genotype $2 a$, was not contained any other groups.

The isolated genes were compared with the isolates by the country identified in the NCBI (Table 3). The phylogenetic tree according to HCV genotypes is shown in Fig. 2.

Table 2. Sample number and group of HCV isolates by HCV genotype

\begin{tabular}{|c|c|c|}
\hline HCV genotype $(n)$ & Group (n) & Sample No. \\
\hline $1 \mathrm{a}(2)$ & - & 4,110 \\
\hline \multirow{6}{*}{$1 \mathrm{~b}(80)$} & KOR-A (33) & $\begin{array}{l}1,33,35,36,39,40,42,43,44,45,47,49,50,51, \\
53,55,56,57,60,61,62,64,67,68,69,70,71, \\
73,78,85,87,88,96\end{array}$ \\
\hline & KOR-B (21) & $\begin{array}{l}5,6,8,9,11,19,38,48,66,72,81,83,86,91,94, \\
97,98,101,106,116,125\end{array}$ \\
\hline & KOR-C (3) & $15,113,122$ \\
\hline & KOR-D (6) & $37,84,95,118,119,124$ \\
\hline & KOR-E (12) & $\begin{array}{l}41,104,107,108,109,111,112,114,115,117, \\
121,126\end{array}$ \\
\hline & $34,93,103,120,127(5)$ & - \\
\hline \multirow{5}{*}{$2 a(42)$} & KOR-A (16) & $\begin{array}{l}2,10,12,13,14,16,17,18,20,21,22,23,24,25, \\
26,27\end{array}$ \\
\hline & KOR-B (19) & $\begin{array}{l}28,29,30,31,32,46,52,58,59,63,75,76,77, \\
79,80,82,89,99,100\end{array}$ \\
\hline & KOR-C (2) & 54,123 \\
\hline & KOR-D (2) & 90,92 \\
\hline & $3,65,74(3)$ & - \\
\hline
\end{tabular}


Table 3. NCBI number and origin of HCV gene by HCV genotype

\begin{tabular}{|c|c|c|c|}
\hline HCV genotype & Abbreviation & Origin & NCBI No. \\
\hline \multirow{6}{*}{$1 a$} & CZE & $\begin{array}{l}\text { Czech } \\
\text { Republic }\end{array}$ & AY725958 \\
\hline & IRN & Iran & HM852067 \\
\hline & ARG & Argentina & JQ065780 \\
\hline & $\mathrm{CHN}$ & China & DQ087244 \\
\hline & GBR & UK & AY766661 \\
\hline & USA & USA & EU862840 \\
\hline \multirow{11}{*}{$1 b$} & IRN & Iran & HM852066 \\
\hline & $\mathrm{CHN}$ & China & AY702953 \\
\hline & ARG & Argentina & JQ273005 \\
\hline & ZAF & $\begin{array}{l}\text { South } \\
\text { Africa }\end{array}$ & HQ396517 \\
\hline & CAN & Canada & EF115582 \\
\hline & BRA & Brazil & AY306266 \\
\hline & RUS & Russia & AY764169 \\
\hline & DEU & Germany & EF175786 \\
\hline & USA-1 & USA & FJ390398 \\
\hline & USA-2 & USA & GU133617 \\
\hline & JPN & Japan & M58335 \\
\hline \multirow{7}{*}{$2 a$} & CAN-1 & Canada & EF115605 \\
\hline & CAN-2 & Canada & JQ318145 \\
\hline & $\mathrm{MCO}$ & Morocco & HQ833239 \\
\hline & JPN & Japan & AB047639 \\
\hline & GBR & UK & AY766689 \\
\hline & DNK & Denmark & KC967476 \\
\hline & $\mathrm{CHN}$ & China & HQ639945 \\
\hline
\end{tabular}


(A)

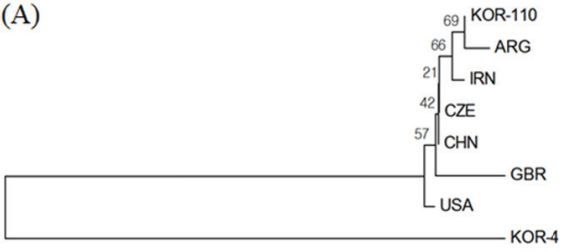

$\longmapsto .005$

(C)

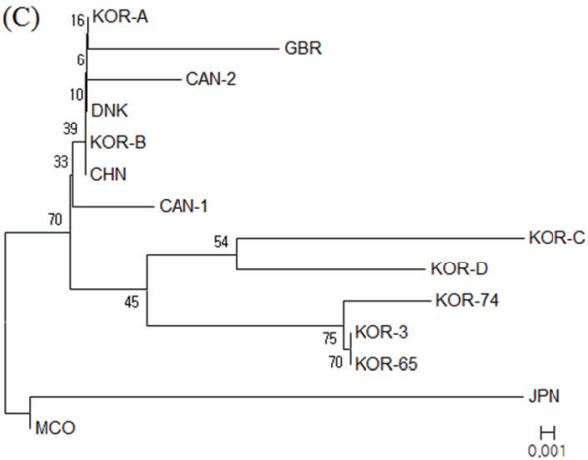

(B)

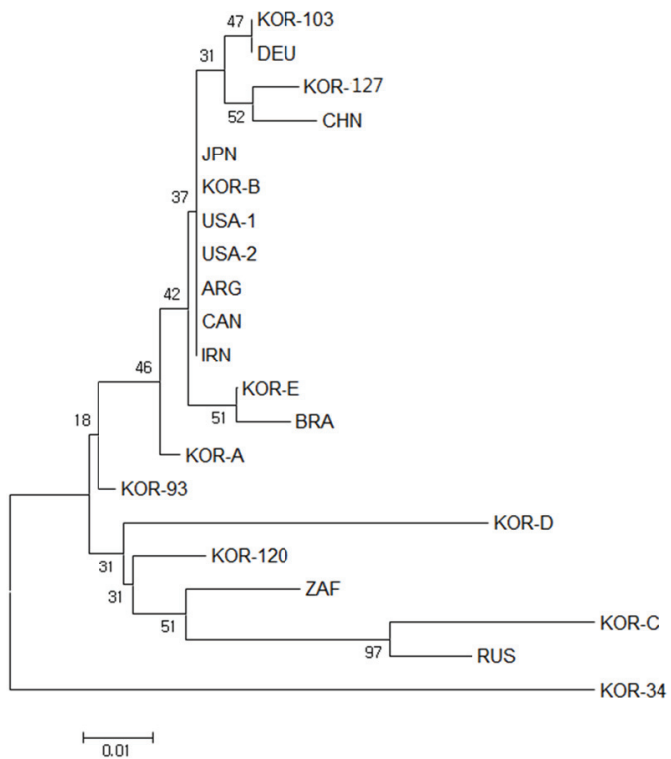

Figure 2. Phylogenetic trees based on HCV isolates and HCV reference strains from other countries

(A) HCV genotype $1 \mathrm{a}$ isolates and references from NCBl; (B) HCV genotype $1 \mathrm{~b}$ isolates and references from NCBl;

(C) HCV genotype $2 a$ isolates and references from NCBI.

\section{Analysis of age and gender according to HCV genotype}

The ages and genders were analyzed according to the HCV genotypes, and the results showed that the mean age of the patients with HCV genotype 1a was 51.5 years, which was younger by approximately 10 years when compared to the patients with genotypes $1 \mathrm{~b}$ or $2 \mathrm{a}$. However, the mean ages of the patients with genotype $1 \mathrm{~b}$ or $2 \mathrm{a}$ were both 60.8 years. The gender distributions according to the genotypes were analyzed and according to the results, all of the patients with HCV genotype 1a were males. The ratio of males was higher by at least $10 \%$ than the ratio of females among the patients with HCV genotype $1 \mathrm{~b}$, and the rations of males and females were similar to each other among the pratients with HCV genotype $1 \mathrm{a}$, although the ratio of females was slightly higher (Table 4).

Table 4. Comparison of age and gender by HCV genotype

\begin{tabular}{lllll}
\hline Characteristics & $1 \mathrm{a}(\mathrm{n}=2)$ & $1 \mathrm{~b}(\mathrm{n}=80)$ & $2 \mathrm{a}(\mathrm{n}=42)$ & Total $(\mathrm{n}=128)$ \\
\hline Age $($ mean \pm SD) & $51.5 \pm 12.0$ & $60.8 \pm 14.4$ & $60.8 \pm 12.9$ & $60.3 \pm 14.1$ \\
Gender $(\mathrm{n}, \%)$ & & & \\
Male & $2(100.0)$ & $44(55.0)$ & $20(47.6)$ & $69(53.9)$ \\
Female & $0(0.0)$ & $36(45.0)$ & $22(52.4)$ & $59(46.1)$ \\
\hline
\end{tabular}

\section{Comparison of the clinical laboratory test results of HCV genotypes $1 \mathrm{~b}$ and $2 \mathrm{a}$}

The clinical properties and states of the patient groups with HCV genotypes $1 \mathrm{~b}$ or $2 \mathrm{a}$ were compared with each other. In addition, each group was compared with the normal control group. The patients with HCV genotype 1a were excluded from this analysis, since the number of isolated patients was too small, and was judged as not being statistically significant (Table 5). 
Both HCV $1 \mathrm{~b}$ and $2 \mathrm{a}$ patients had higher AFP, AST, ALT, ALP, $\gamma$-GTP, apoB, and apoE values compared with the normal control group. In particular, apoB and apoE levels were statistically significantly higher in the HCV 2a patients $(p<0.05)$ and apoE levels were significantly higher in the HCV $1 \mathrm{~b}$ patients $(p<0.000)$. Total cholesterol, HDL, and LDL levels were lower in the both HCV $1 \mathrm{~b}$ and $2 \mathrm{a}$ patients $(p<0.05)$ and TG levels were higher in the HCV 2a patients. However, there were no significant differences in the all clinical biomarkers between the HCV $1 \mathrm{~b}$ and 2a patients ( $p>0.05)$ (Table 5).

Table 5. Comparison of clinical characteristics in HCV genotype $1 \mathrm{~b}$ and $2 \mathrm{a}$

\begin{tabular}{|c|c|c|c|c|c|c|}
\hline Characteristics & $1 b$ & $2 a$ & Control & $p^{a}$ & $p^{b}$ & $p^{c}$ \\
\hline AFP (ng/ml) & $109.2 \pm 14.4$ & $32.0 \pm 107.2$ & $2 \pm 1.1$ & 0.721 & 0.636 & 0.412 \\
\hline Total protein (g/dl) & $7.4 \pm 0.8$ & $7.5 \pm 0.6$ & $6.8 \pm 1.6$ & 0.517 & 0.476 & 0.663 \\
\hline Albumin (g/dl) & $3.9 \pm 0.6$ & $4.1 \pm 0.5$ & $4.4 \pm 0.1$ & 0.346 & 0.362 & 0.120 \\
\hline AST (IU/L) & $59.5 \pm 57.7$ & $56.7 \pm 80.6$ & $21.4 \pm 4.6$ & 0.000 & 0.176 & 0.826 \\
\hline ALT (IU/L) & $48.7 \pm 45.6$ & $47.7 \pm 62.8$ & $16.5 \pm 3.6$ & 0.000 & 0.003 & 0.919 \\
\hline Total bilirubin (mg/dl) & $1.3 \pm 2.0$ & $0.8 \pm .0 .3$ & $0.8 \pm 0.3$ & 0.709 & 0.531 & 0.044 \\
\hline ALP (IU/L) & $316.7 \pm 2.0$ & $264.0 \pm 70.6$ & $242.5 \pm 46.3$ & 0.584 & 0.557 & 0.114 \\
\hline$\gamma$-GTP (IU/L) & $73.5 \pm 91.1$ & $59.46 \pm 94.8$ & $19.2 \pm 6.4$ & 0.000 & 0.190 & 0.469 \\
\hline BUN (mg/dl) & $19.5 \pm 14.7$ & $19.9 \pm 16.2$ & $16.2 \pm 3.6$ & 0.663 & 0.661 & 0.903 \\
\hline Creatinine (mg/dl) & $1.3 \pm 0.9$ & $1.5 \pm 1.7$ & $0.954 \pm 0.1$ & 0.293 & 0.297 & 0.362 \\
\hline TG $(\mathrm{mg} / \mathrm{dl})$ & $127.2 \pm 106.9$ & $115.1 \pm 48.0$ & $112 \pm 66.9$ & 0.668 & 0.872 & 0.562 \\
\hline Total cholesterol (mg/dl) & $164.7 \pm 49.8$ & $166.2 \pm 30.9$ & $224.3 \pm 32.0$ & 0.000 & 0.000 & 0.871 \\
\hline $\mathrm{HDL}(\mathrm{mg} / \mathrm{dl})$ & $47.1 \pm 13.2$ & $49.8 \pm 15.0$ & $74.8 \pm 27.2$ & 0.012 & 0.002 & 0.445 \\
\hline LDL (mg/dl) & $104.1 \pm 33.5$ & $102.7 \pm 22.8$ & $135.2 \pm 43.8$ & 0.021 & 0.048 & 0.684 \\
\hline ApoB $(\mu \mathrm{g} / \mu \mathrm{l})$ & $9.2 \pm 16.0$ & $5.4 \pm 5.6$ & $1.93 \pm 1.3$ & 0.155 & 0.001 & 0.056 \\
\hline ApoE $(\mu \mathrm{g} / \mu \mathrm{l})$ & $0.220 \pm 0.173$ & $0.198 \pm 0.167$ & $0.058 \pm 0.016$ & 0.000 & 0.000 & 0.504 \\
\hline
\end{tabular}

AFP, $\alpha$-fetoprotein; AST, asparatate aminotransferase; ALT, alanine aminotransferase; ALP, alkaline phosphatase; $\gamma$-GTP, $\gamma$-glutamyltransferase; BUN, TG, triglyceride; HDL, high density lipoprotein; LDL, low density lipoprotein; ApoB, apolipoprotein B; ApoE, apolipoprotein E.

${ }^{a}$ compared with patients of HCV genotype $1 \mathrm{~b}$ and Normal control

${ }^{b}$ compared with patients of HCV genotype $2 a$ and Normal control

compared with patients of HCV genotype $1 \mathrm{~b}$ and $2 \mathrm{a}$

The apoE genetic polymorphisms were determined according to the classified HCV genotypes. According to the results of all of the patients with HCV genotype $1 \mathrm{a}$, they were apoE type $\varepsilon 3 / \varepsilon 3$. Among the patients with HCV genotype $1 \mathrm{~b}$, type $\varepsilon 3 / \varepsilon 3$ was the most prevalent at $78.5 \%$, followed by $\varepsilon 2 / \varepsilon 3$ and $\varepsilon 3 / \varepsilon 4$ in order of precedence. Among the patients with HCV 
genotype $2 \mathrm{a}$, type $\varepsilon 3 / \varepsilon 3$ was the most prevalent at $85.7 \%$, followed by $\varepsilon 3 / \varepsilon 4, \varepsilon 2 / \varepsilon 3$, and $\varepsilon 2 / \varepsilon 4$ in order of precedence. Among the patients with HCV genotype 2 a, type $\varepsilon 2 / \varepsilon 4$ was specifically identified, and the isolation ratio of $\varepsilon 3 / \varepsilon 3$ was shown to be higher by at least $7.0 \%$ than in genotype $1 \mathrm{~b}$. The isolation ratios of the other subtypes were lower. The apoE genotypes according to the HCV genotypes were cross-analyzed, and the correlations were found to be statistically significant $(p<0.05)$ (Table 6).

Table 6. Comparison of apolipoprotein E genotype by HCV genotype

\begin{tabular}{ccccccccc}
\hline \multirow{2}{*}{ HCV genotype } & \multicolumn{9}{c}{ Apolipoprotein E genotype $(\mathrm{n}, \%)$} & \multirow{2}{*}{ Total } & $\chi^{2}(p)$ \\
\cline { 2 - 6 } & $\varepsilon 2 / \varepsilon 2$ & $\varepsilon 2 / \varepsilon 3$ & $\varepsilon 2 / \varepsilon 4$ & $\varepsilon 3 / \varepsilon 3$ & $\varepsilon 3 / \varepsilon 4$ & $\varepsilon 4 / \varepsilon 4$ & & $2(100.0)$ \\
1a & $0(0.0)$ & $0(0.0)$ & $0(0.0)$ & $2(100.0)$ & $0(0.0)$ & $0(0.0)$ & & 19.918 \\
$1 b$ & $0(0.0)$ & $10(12.5)$ & $0(0.0)$ & $63(78.7)$ & $7(8.8)$ & $0(0.0)$ & $80(100.0)$ & $(0.018)$ \\
$2 a$ & $0(0.0)$ & $2(4.8)$ & $1(2.4)$ & $36(85.7)$ & $3(7.1)$ & $0(0.0)$ & $42(100.0)$ & \\
\hline
\end{tabular}

The apoE genotypes were identified using the apoE alleles according to the classified HCV genotypes, and the results indicated that the ratios of the apoE $\varepsilon 3$ and $\varepsilon 4$ alleles among the patients with genotype $1 \mathrm{~b}$ and $2 \mathrm{a}$ were similar to each other. However, the ratio of the $\varepsilon 2$ allele among the patients with genotype $1 \mathrm{~b}$ was higher by approximately 2 times that among the patients with genotype $2 \mathrm{a}$ (Table 7 ).

Table 7. Comparison of apolipoprotein E gene allele by HCV genotype

\begin{tabular}{|c|c|c|c|c|}
\hline \multirow{2}{*}{$\begin{array}{c}\text { HCV } \\
\text { genotype }\end{array}$} & \multicolumn{3}{|c|}{ ApoE allele (\%) } & \multirow{2}{*}{ Total } \\
\hline & $\varepsilon 2$ & $\varepsilon 3$ & $\varepsilon 4$ & \\
\hline $1 a$ & 0.0 & 100.0 & 0.0 & 100.0 \\
\hline $1 b$ & 6.3 & 89.2 & 4.4 & 100.0 \\
\hline $2 a$ & 3.6 & 91.7 & 4.8 & 100.0 \\
\hline
\end{tabular}

In the HCV $1 \mathrm{~b}$ patients, the $\varepsilon 3 / \varepsilon 3$ group had higher AFP and ALP levels than the $\varepsilon 2 / \varepsilon 3$ apoE genotype group and the $\varepsilon 2 / \varepsilon 3$ group had higher AST and ALT levels than the $\varepsilon 3 / \varepsilon 3$ apoE genotype group. In the HCV 2a patients, the $\varepsilon 2 / \varepsilon 3 \mathrm{group}$ had higher AFP and ALP levels than the $\varepsilon 3 / \varepsilon 3$ apoE genotype group. And the $\varepsilon 2 / \varepsilon 3$ group and $\varepsilon 3 / \varepsilon 3$ apoE genotype groups had the same levels of AST, and ALT.

The $\varepsilon 2 / \varepsilon 3$ group in the HCV $1 b$, and 2 a patients had higher levels of $\gamma$-GTP. The $\varepsilon 3 / \varepsilon 3$ group in the HCV $1 b$, and $2 a$ patients had higher levels of TG. The $\varepsilon 2 / \varepsilon 3$ group in the HCV $1 \mathrm{~b}$, and 2a patients had the lowest LDL levels. HDL levels were generally low when not accounting for apoE genotype or hepatitis type. In the HCV $1 \mathrm{~b}$ patients, apoB and apoE levels were higher in the $\varepsilon 3 / \varepsilon 3$ group. In the HCV 2a patients, apoB and apoE levels were higher in the $\varepsilon 3 / \varepsilon 3$ and $\varepsilon 3 / \varepsilon 3$ groups, respectively (Table 8 ).

Table 8. Comparison of clinical characteristics in HCV genotype by apoE polymorphism

\begin{tabular}{lccccc}
\hline Characteristics & HCV genotype & $\varepsilon 2 / \varepsilon 3$ & $\varepsilon 2 / \varepsilon 4$ & $\varepsilon 3 / \varepsilon 3$ & $\varepsilon 3 / \varepsilon 4$ \\
\hline \multirow{2}{*}{$\mathrm{n}$} & $1 \mathrm{~b}$ & 10 & 0 & 63 & 7 \\
\cline { 2 - 6 } & $2 \mathrm{a}$ & 2 & 1 & 36 & 3 \\
\hline \multirow{2}{*}{ AFP $(\mathrm{ng} / \mathrm{ml})$} & $1 \mathrm{~b}$ & $3.3 \pm 1.4$ & - & $111.1 \pm 131.2$ & $188.6 \pm 82.3$ \\
\hline & $2 \mathrm{a}$ & $62.8 \pm 71.3$ & 3.8 & $14.6 \pm 89.2$ & $3.0 \pm 4.1$ \\
\hline
\end{tabular}




\begin{tabular}{|c|c|c|c|c|c|}
\hline \multirow{2}{*}{ Total protein (g/dl) } & $1 b$ & $7.8 \pm 1.0$ & - & $7.4 \pm 0.5$ & $7.1 \pm 0.9$ \\
\hline & $2 a$ & $7.1 \pm 0.9$ & 6.7 & $7.5 \pm 1.0$ & $7.4 \pm 0.7$ \\
\hline \multirow{2}{*}{ Albumin (g/dl) } & $1 b$ & $4.1 \pm 0.9$ & - & $3.9 \pm 0.2$ & $3.8 \pm 0.8$ \\
\hline & $2 a$ & $3.7 \pm 0.2$ & 3.8 & $4.2 \pm 0.9$ & $3.8 \pm 0.6$ \\
\hline \multirow{2}{*}{ AST (IU/L) } & $1 b$ & $59.6 \pm 67.1$ & - & $62.4 \pm 43.3$ & $33.7 \pm 48.7$ \\
\hline & $2 a$ & $56.2 \pm 58.3$ & 19.0 & $60.2 \pm 66.8$ & $34.3 \pm 46.1$ \\
\hline \multirow{2}{*}{ ALT (IU/L) } & $1 b$ & $51.5 \pm 49.3$ & - & $49.9 \pm 40.8$ & $34.4 \pm 28.9$ \\
\hline & $2 a$ & $47.9 \pm 62.2$ & 33.0 & $51.6 \pm 50.1$ & $19.3 \pm 21.7$ \\
\hline \multirow{2}{*}{ Total bilirubin (mg/dl) } & $1 b$ & $0.9 \pm 0.1$ & - & $1.3 \pm 2.1$ & $0.9 \pm 0.4$ \\
\hline & $2 a$ & $0.9 \pm 0.3$ & 1.0 & $0.8 \pm 1.1$ & $0.8 \pm 0.1$ \\
\hline \multirow{2}{*}{ ALP (IU/L) } & $1 b$ & $291.1 \pm 132.2$ & - & $327.3 \pm 189.1$ & $267.3 \pm 112.1$ \\
\hline & $2 a$ & $271.7 \pm 122.2$ & 188.0 & $266.9 \pm 105.2$ & $277.0 \pm 141.2$ \\
\hline \multirow{2}{*}{$\gamma$-GTP (IU/L) } & $1 b$ & $93.4 \pm 81.1$ & - & $72.1 \pm 66.1$ & $57.7 \pm 38.2$ \\
\hline & $2 a$ & $89.8 \pm 71.3$ & 23.0 & $61.4 \pm 81.1$ & $38.0 \pm 31.4$ \\
\hline \multirow{2}{*}{ BUN (mg/dl) } & $1 b$ & $26.4 \pm 11.2$ & - & $18.7 \pm 10.1$ & $16.1 \pm 10.8$ \\
\hline & $2 a$ & $25.3 \pm 13.1$ & 17.6 & $19.1 \pm 9.7$ & $33.0 \pm 21.5$ \\
\hline \multirow{2}{*}{ Creatinine (mg/dl) } & $1 b$ & $1.2 \pm 0.8$ & - & $1.3 \pm 1.5$ & $1.1 \pm 0.9$ \\
\hline & $2 a$ & $1.2 \pm 0.6$ & 0.9 & $1.4 \pm 1.1$ & $3.7 \pm 2.1$ \\
\hline \multirow{2}{*}{ Total cholesterol (mg/dl) } & $1 b$ & $154.4 \pm 41.7$ & - & $167.8 \pm 41.6$ & $152.0 \pm 32.8$ \\
\hline & $2 a$ & $148.9 \pm 26.6$ & 214.0 & $162.8 \pm 44.5$ & $170.3 \pm 31.3$ \\
\hline \multirow{2}{*}{$\mathrm{TG}(\mathrm{mg} / \mathrm{dl})$} & $1 b$ & $107.0 \pm 88.0$ & - & $134.0 \pm 82.5$ & $106.3 \pm 41.6$ \\
\hline & $2 a$ & $112.3 \pm 68.2$ & 92.0 & $114.6 \pm 94.0$ & $99.5 \pm 48.8$ \\
\hline \multirow{2}{*}{$\mathrm{HDL}(\mathrm{mg} / \mathrm{dl})$} & $1 b$ & $46.2 \pm 12.6$ & - & $46.0 \pm 13.0$ & $54.4 \pm 17.5$ \\
\hline & $2 a$ & $42.5 \pm 10.6$ & - & $50.0 \pm 12.8$ & $54.0 \pm 8.5$ \\
\hline \multirow{2}{*}{ LDL (mg/dl) } & $1 b$ & $81.6 \pm 38.2$ & - & $108.3 \pm 30.8$ & $106.8 \pm 11.1$ \\
\hline & $2 a$ & $86.1 \pm 32.4$ & - & $99.3 \pm 27.7$ & $114.5 \pm 14.5$ \\
\hline \multirow{2}{*}{ ApoB $(\mu \mathrm{g} / \mu \mathrm{l})$} & $1 b$ & $5.1 \pm 6.6$ & - & $10.1 \pm 11.4$ & $6.9 \pm 11.0$ \\
\hline & $2 a$ & $5.6 \pm 6.7$ & 1.6 & $5.5 \pm 7.9$ & $2.9 \pm 3.9$ \\
\hline \multirow{2}{*}{ ApoE $(\mu \mathrm{g} / \mu \mathrm{l})$} & $1 b$ & $0.180 \pm 0.092$ & - & $0.236 \pm 0.150$ & $0.133 \pm 0.111$ \\
\hline & $2 a$ & $0.199 \pm 0.117$ & 0.126 & $0.198 \pm 0.177$ & $0.109 \pm 0.096$ \\
\hline
\end{tabular}

AFP, $\alpha$-fetoprotein; AST, asparatate aminotransferase; ALT, alanine aminotransferase; ALP, alkaline phosphatase; $\gamma$-GTP, $\gamma$-glutamyltransferase; BUN, TG, triglyceride; HDL, high density lipoprotein; LDL, low density lipoprotein; ApoB, apolipoprotein B; ApoE, apolipoprotein $\mathrm{E}$. 


\section{DISCUSSION}

Many previous studies have investigated the distribution of HCV genotypes, in Korea. Whereas genotypes $1 \mathrm{~b}$ and $2 \mathrm{a}$ have been isolated at similar frequencies in Korea, in the present study, genotype $1 \mathrm{~b}$ was more frequently isolated by approximately two times than genotype $2 \mathrm{a}$, as the ratio was $64.5 \%(80 / 124)$. This bias is considered attributable to the fact that the clinical samples were obtained from only one medical institution located in the Gyeonggi-do Province. In previous study, Shon et al. reported that the prevalence of HCV infection differs by regions as well as towns in the Korea, and is highest in Busan, Jeonnam, and Gyeongnam. Therefore, the genotypes of the isolated HCVs may be different by region (14 17).

We obtained $124 \mathrm{HCV}$ positive samples that were successfully sequenced. To analyze the distribution of HCV genotypes, three phylogenetic trees were generated, each representing one of the three genotypes identified in this study, 1a, $1 \mathrm{~b}$, and 2a (Fig.2.). The phylogenetic tree for genotype $1 \mathrm{a}$ was showed two clear separate groups. In the genotype $1 \mathrm{~b}$ and $2 \mathrm{a}$ trees, major groups distributed throughout the trees. These showed that the distribution of HCV genotypes of isolates from this study is complex. Our phylogeny analysis need to be verified in new further studies with large random sampled sequences.

HCV infection is associated with a decrease in serum levels of total cholesterol, LDL cholesterol (18). In previous study, we already confirmed that HCV infection are strongly associated with low levels of main cholesterol biomarker (HDL, LDL, and total cholesterol) (12). We reconfirmed it through this study. In addition, apoB and apoE levels were higher in both HCV $1 \mathrm{~b}$ and 2a patients than in healthy controls. ApoE and B are both components of VLDL and are thought to play important roles in the HCV life cycles. Some studies have reported that both apolipoproteins are required for HCV assembly and secretion (19 21). HCV 1b has more of an effect than HCV 2a due to high levels of TG, apoB, and apoE. However, there were no statistically significant differences between HCV genotype $1 \mathrm{~b}$ and $2 \mathrm{a}$.

Price et al. reported that apolipoprotein $\varepsilon 3$ allele is associated with persistent HCV infection. Also, Gomma et al. suggest that apo $\varepsilon 3$ allele is considered as a particular risk factor in $\mathrm{HCV}$ patients $(22,23)$. In the present study, the correlations between the HCV genotypes and apoE genotypes were analyzed. The HCV $1 \mathrm{~b}$ and $2 \mathrm{a}$ both had a high distribution of haplotype $\varepsilon 3 / \varepsilon 3$ $78.7 \%$ (63/80), 85.7\% (36/42), respectively. The distribution of $\varepsilon 3 / \varepsilon 3$ type is about $75 \%$ in normal people (11, 24). Therefore, $\varepsilon 3 / \varepsilon 3$ is more common type in HCV $1 b$ and HCV 2a. Especially, genotype 2a was shown to be higher than the ratio of type $\varepsilon 3 / \varepsilon 3$ generally identified in Korea, indicating that genotype $2 a$ is correlated with type $\varepsilon 3 / \varepsilon 3$. We anticipate that the apoE $\varepsilon 3$ allele is the most common type in HCV genotype $1 \mathrm{~b}(89.2 \%)$ and $2 \mathrm{a}(91.7 \%)$. As a result of apoE genotyping, we confirmed an association with HCV infection and the apoE $\varepsilon 3$ allele. However, the ratios of the apoE 83 allele among the patients with genotype $1 \mathrm{~b}$ and $2 \mathrm{a}$ were similar to each other (were not statistically significant). The present study has some limitations; The problem of clinical samples (relatively small sample size and limitation of collection region), and exclusion of the patient's underlying medical conditions. Therefore, we need further studies to verify our findings.

In conclusion, the HCV genotypes were identified among the 124 patients infected with HCV, and the genetic characteristics of the HCV genotype were analyzed. In addition, the results of clinical laboratory test were comparatively analyzed according to the classified genotypes. According to the results the patients with HCV genotype $1 \mathrm{~b}$ showed higher values of liver damage related indicators and apoB expression than the patients with HCV genotype $2 \mathrm{a}$. The fat related indicators and apoE expression were not different between the genotypes. The apoE $\varepsilon 3$ and $\varepsilon 2$ allele were more frequently identified in the patients with genotype $2 a$ and $1 b$, respectively. Analyses with large scale samples collected from diversity of region are needed in order to verify the relationship between HCV genotype and apolipoprotein.

\section{ACKNOWLEDGMENTS}

This research was supported by the Basic Science Research Program through the National Research Foundation of Korea (NRF) funded by the Ministry of Education, Science and Technology (2012007586) and by Brain Busan 21 (BB21). 


\section{REFERENCES}

1) Lanini S, Easterbrook PJ, Zumla A, Ippolito G. Hepatitis C: global epidemiology and strategies for control. Clin Microbiol Infect 2016;22:833-38.

2) Umar S, Yasir W, Muhammad A. Hepatitis B and hepatitis $C$ viruses: a review of viral genomes, viral induced host immune responses, genotypic distributions and worldwide epidemiology. Asian Pac J Trop Dis 2014;4:88-96.

3) Shin HR, Kim JY, Kim JI, Lee DH, Yoo KY, Lee DS, et al. Hepatitis B and C virus prevalence in a rural area of South Korea: the role of acupuncture. Br J Cancer 2002:87:314-8.

4) Cho EJ, Jeong SH, Han BH, Lee SU, Yun BC, Park ET. Hepatitis C virus (HCV) genotypes and the influence of HCV subtype $1 \mathrm{~b}$ on the progression of chronic hepatitis $\mathrm{C}$ in Korea: a single center experience. Clin Mol Hepatol 2012;18:219-24.

5) Hnatyszyn HJ. Chronic hepatitis $C$ and genotyping: the clinical significance of determining HCV genotypes. Antivir Ther 2005:10:1-11.

6) Chang KS, Jiang J, Cai Z, Luo G. Human apolipoprotein e is required for infectivity and production of hepatitis $C$ virus in cell culture. J Virol 2007;81:13783-93.

7) Fierro NA, Gonzalez-Aldaco K, Torres-Valadez R, Martinez-Lopez E, Roman S, Panduro A. Immunologic, metabolic and genetic factors in hepatitis C virus infection. World J Gastroenterol 2014;20:3443-56.

8) Felmlee DJ, Hafirassou ML, Lefevre M, Baumert TF, Schuster C. Hepatitis C virus, cholesterol and lipoproteins--impact for the viral life cycle and pathogenesis of liver disease. Viruses 2013;5:1292-324.

9) Jiang J, Luo G. Apolipoprotein E but not B is required for the formation of infectious hepatitis $C$ virus particles. J Virol 2009;83:12680-91.

10) Jang ES, Won JE, Jung JI, Lee SH, Kim JW, Jeong SH. The effect of antiviral therapy on serum cholesterol levels in chronic hepatitis C. Gut Liver 2011:5:356-62.

11) Kim YS, Paeng JR, Woo JT, Kim SW, Yang IM, Kim JW, et al. Apolipoprotein E genotypes of normal and hyperlilpidemic subjects. J Korean Med Sci 1993;8:262-6.

12) Jo HJ, Park GN, Kim HR, Kim MJ, Shin KA, et al. Differences in Hematological Characteristics, Including Cholesterol and Apolipoprotein B and E, between Hepatitis B Virus and Hepatitis C Virus Patients in Korea. J Bacteriol Virol 2016;46:152-8.

13) Gause JW, Day RJ, Caraway CA, Poon WW, Rohn TT. Evaluation of Apolipoprotein E fragmentation as a biomarker for Alzheimer's disease. J Neurol Neurol Disord 2017;3:204.

14) Shon HS, Choi HY, Kim JR, Ryu SY, Lee YJ, Lee MJ, et al. Comparison and analysis of the prevalence of hepatitis $C$ virus infection by region in the Republic of Korea during 2005-2012. Clin Mol Hepatol 2015;21:249-56.

15) Jeong $\mathrm{SH}$, Jang ES, Choi HY, Kim KA, Chung W, et al. Current status of hepatitis $C$ virus infection and countermeasures in South Korea. Epidemiol Health 2017:13:39:e2017017. 
16) Seong MH, Kil H, Kim YS, Bae SH, Lee YJ, Lee HC, et al. Clinical and epidemiological features of hepatitis $C$ virus infection in South Korea: a prospective, multicenter cohort study. J Med Virol 2013:85:1724-33.

17) Messina JP, Humphreys I, Flaxman A, Brown A, Cooke GS, Pybus OG, et al. Global distribution and prevalence of hepatitis $C$ virus genotypes. Hepathology 2015;61:77-87

18) Bassendine MF, Sheridan DA, Bridge SH, Felmlee DJ, Neely RD. Lipids and HCV. Semin Immunopathol 2013;35: 87-100.

19) Gastaminza P, Cheng G, Wieland S, Zhong J, Liao W, Chisari FV. Cellular determinants of hepatitis $C$ virus assembly, maturation, degradation, and secretion. J Virol 2008;82:2120-9.

20) Huang H, Sun F, Owen DM, Li W, Chen Y, Gale M Jr, et al. Hepatitis C virus production by human hepatocytes dependent on assembly and secretion of very low density lipoproteins. Proc Natl Acad Sci U S A 2007;104:5848-53.

21) Icard V, Diaz O, Scholtes C, Perrin-Cocon L, Ramière C, Bartenschlager R, et al. Secretion of hepatitis $C$ virus envelope glycoproteins depends on assembly of apolipoprotein B positive lipoproteins. PloS One 2009;4:e4223.

22) Price DA, Bassendine MF, Norris SM, Golding C, Toms GL, Schmid ML, et al. Apolipoprotein epsilon3 allele is associated with persistent hepatitis C virus infection. Gut 2006:55:715-8.

23) Gomaa HE, Mahmoud M, Saad NE, Saad-Hussein A, Ismail S, Thabet EH, et al. Impact of ApoE gene polymorphism on HCV therapy related outcome in a cohort of HCV Egyptian patients. J Genet Eng Biotechnol 2018;16:47-51.

24) Shin MH, Kim HN, Cui LH, Kweon SS, Park KS, Heo H, et al. The effect of apolipoprotein E polymorphism on lipid levels in Korean adults. J Korean Med Sci 2005:20:361-6. 